\title{
Cross-cultural adaptation of the Toronto Western Spasmodic Torticollis Rating Scale (TWSTRS) to Brazilian Portuguese
}

\author{
Flávio Augusto Sekeff-Sallem¹, Paulo Caramelli², Egberto Reis Barbosa
}

\begin{abstract}
Cervical dystonia (CD) is a prevalent and incapacitating movement disorder which needs a thorough clinical evaluation of every patient to better tailor treatment strategies. In Brazil, there are no validated CD scales that measure the burden of dystonia. The aim of our study was to translate and adapt the Toronto Western Spasmodic Torticollis Rating Scale (TWSTRS) to Brazilian Portuguese. After translation and back-translation according to international methods, a pre-test was carried out with 30 patients. Patients under 8 years of formal schooling had severe difficulty in understanding the whole scale. The scale went through a remodeling process, without loss of its conceptual and semantic properties. The new scale was tested in 15 patients, with good understanding scores. We are now in the process of validation of the adapted scale.

Key words: cervical dystonia, scales, cross-cultural adaptation.
\end{abstract}

Adaptação transcultural da escala de distonia cervical de Toronto (TWSTRS) para o português

\section{RESUMO}

Distonia cervical (DC) é um transtorno de movimento prevalente e incapacitante, sendo uma avaliação global e consistente de cada paciente necessária para a melhor intervenção diagnóstica e terapêutica. No Brasil, não há escalas validadas para avaliar o impacto da DC. O objetivo deste trabalho foi traduzir e adaptar uma escala mundialmente conhecida e usada, a Toronto Western Spasmodic Torticollis Rating Scale (TWSTRS) para o português. Após a tradução e retro-tradução da escala segundo as normas e critérios internacionais, realizamos o pré-teste com 30 pacientes, sendo que o completo entendimento da escala ficou prejudicado nos pacientes com escolaridade abaixo de 8 anos. Tornou-se necessária a re-adaptação da escala, com modificação de alguns elementos, tentando manter-se sua integridade conceitual e semântica. Após pré-teste adicional com 15 pacientes, verificou-se que a escala foi completamente entendida por praticamente todos os pacientes. A validação da escala está em andamento.

Palavras-chave: distonia cervical, escalas, adaptação trans-cultural.

Cervical dystonia (CD) is a common focal dystonia ${ }^{1,2}$ and is characterized by twisting or turning of the neck, or deviation of the head, caused by involuntary muscle contraction ${ }^{2,3}$. Its prevalence ranges from 57 to 90 cases per million in USA and Europe, although figures as high as 233 per million have been found in Finland ${ }^{2}$.
The clinical picture of $\mathrm{CD}$ is quite heterogeneous, with variations in rhythm, speed, amplitude, duration and direction of the dystonic movements ${ }^{1,4} \cdot \mathrm{Pa}$ tients may present with head deviations in one plane only or present complex movements of the head and neck around multiple axes ${ }^{5}$.
Flávio Augusto Sekeff-Sallem

Rua Dr. Diogo de Faria 1226 / ap. 24 04037-004 São Paulo SP - Brasil E-mail: fass_1998@yahoo.com

\section{Received 12 July 2010}

Received in final form 22 September 2010 Accepted 29 September 2010
${ }^{1}$ Neurology Division, Hospital das Clínicas of the University of São Paulo School of Medicine, São Paulo SP, Brazil; ${ }^{2}$ Department of Internal Medicine, Faculty of Medicine, Federal University of Minas Gerais, Belo Horizonte MG, Brazil. 
Besides motor abnormalities, patients may also suffer from pain. About 70-80\% of CD patients complain of neck pain, which can be intermittent or continuous and contribute significantly to disability ${ }^{6}$. This combination of signs and symptoms may ultimately lead to impairment of quality of life (QOL), as patients may suffer from disability due to cervical pain or incapacitating involuntary head movements, social embarrassment, and difficulties in performing daily life and social activities ${ }^{6,7}$.

The impact CD has on QOL of affected individuals must be measured by validated tools so to produce reliable data necessary to better understand its natural history, evaluate the response to treatment and to collect accurate information for clinical trials. There are several scales that have been used to evaluate $C D^{1,8-13}$, but none has been validated to Brazilian Portuguese so far.

The Toronto Western Spasmodic Torticollis Rating Scale (TWSTRS $)^{1}$, a investigator-applied scale, is the gold standard tool for evaluation of CD. It is composed of three subscales designed to assess the motor aspects of $C D$, measure the impact of CD on activities of daily living, and quantify pain caused by CD and its consequences on life of affected individuals.

In this paper, we present the results of the cross-cultural adaptation of the TWSTRS to Brazilian Portuguese.

\section{METHOD}

This study was carried out at the Movement Disorders Division of the Hospital das Clínicas of the University of São Paulo School of Medicine, in São Paulo, SP, Brazil.

The inclusion criteria were: [1] clinical diagnosis of cervical dystonia; [2] 18 years of age or older; [3] patients not presenting cognitive deficits, as indicated by scores above education-adjusted cut-off values at the MiniMental State Examination (MMSE) ${ }^{14,15}$; [4] full acceptance by the patient in participating into the study, signing the free informed consent. The study was approved by the local ethics board committee. The original authors authorized the full adaptation/validation of the scale.

The steps taken for the adaptation were in accordance with the guidelines proposed by Guillemin et al. ${ }^{16}$, and have been replicated by several authors ${ }^{17-20}$. First, the entire original scale was translated into Brazilian Portuguese by two independent Portuguese-speaking translators who were aware of the objectives of the study. This translation was done word for word, and the translators translated the entire scale. This translated scale was then back translated by two independent English-speaking translators who were not aware of the objectives of the scale. This back-translated scale was discussed with the translators, and so a final translated version of the original scale was produced.

This version underwent revision by a committee composed of three neurologists with expertise in movement disorders. Each judge received a copy of the original scale and of its translated version, along with semantic and cultural questionnaire forms. The rate of agreement among judges was over $80 \%$, with few suggestions as for some items of the scale that seemed to be more culturally appropriate, which were carried out after discussion between the author and the judges. So, a revised version of the scale was produced.

We then carried out a pre-test with $30 \mathrm{CD}$ patients, separated in three 10-patient groups according to their educational level: [1] $\leq 4$ years; [2] 5 to 7 years; and [3] $\geq 8$ years of schooling, aiming to evaluate how those patients would understand the revised scale. As the motor subscale is clinically objective and the scale is not self-applicable, we decided to perform the pre-test only with the Activities of Daily Living and Pain subscales. The adaptation followed the methods of applicability of the original scale, and the questions were read to the patients by the investigators. All patients gave their written informed consent.

\section{RESULTS}

All patients were cognitively normal, with mean MMSE scores of $25.8 \pm 3.4$ points. The following results have been found:

[1] In the group of individuals of $\geq 8$ years of schooling, $80 \%$ of the patients understood the scale as a whole. One patient did not understand question 3 of item A of the Disability Scale section (Working at lower than usual occupation level; most activities hampered, all possible but with less than satisfactory performance in some activities), and one patient did not understand questions 1 (Normal work expectations with satisfactory performance at usual level of occupation but some interference by torticollis) and 3 of item A. One patient made some comments about the item Disability due do Pain of the Pain Scale section, as she believed questions 1 (Pain is quite bothersome but not a source of disability) and 2 (Pain definitely interferes with some tasks but is not a major contributor to disability) of the translated version were very similar to each other. So, modifications in these questions were performed. We tried to keep the intended capacity of the original scale to reliably measure pain in these patients.

[2] In the group with 5 to 7 years of education, 30\% of the patients understood the scale as a whole. Seven patients did not understand one or more questions, in special those containing the terms Unlimited ability, Limited ability, and Work Performance, and five patients did not understand one or more questions of the Pain Scale.

[3] In the less educated group ( $\leq 4$ years), no patient could understand the whole scale, and the questions dis- 
playing the terms Unlimited ability and Limited ability, besides the item Disability due to Pain of the Pain Scale were of much difficult interpretation by those patients.

These results led us to consider that this revised version would not be suitable to be applied to most patients attending public and university hospitals in Brazil, as only those with eight or more years of formal education were able to understand the whole scale. This subset of individuals does not represent at all the distribution of education within the Brazilian population, especially among the elderly.

Hence, we decided to carry out a new adaptation of the revised scale, aiming at producing a reliable and easier-to-understand scale. First, each sentence was revised by the authors, and the items of most difficult interpretation by the patients were reformatted trying by all means to keep the real semantic properties of the original scale. The modifications were as follows:

[1] Some sentences were completely reformatted because many patients couldn't understand it at all, like the second sentence of the Disability Scale, "Normal work expectations with satisfactory performance at usual level of occupation but some interference by torticollis" or some sentences of the third item of the Pain Scale.

[2] Sentences beginning with "unlimited ability", "unable", "limited ability", "unlimited activities" and "work performance" were changed to more understandable versions, because many patients were unable to understand the meaning of these expressions.

[3] Some long sentences were shortened because many patients, when were told the whole sentence, could not connect the end with the beginning of the sentence (there were no demented or cognitively impaired patients).

[4] The item Duration of Pain of the Pain Subscale was changed because many patients were unable to mentally work percentages, and we preferred to use a time scale mathematically equivalent to the percentages. Thus, less than $10 \%$ was equivalent to less than 3 hours; between 10 and $25 \%$ was equivalent to 3 to 6 hours; and so on.

A new committee composed of one neurologist with expertise in movement disorders and one Portuguese university teacher with Master degree was constituted. Each one received the original scale, the previous revised scale and the reformatted scale. Again, the rate of agreement between the new judges was over $80 \%$ and no great modifications were suggested.

We opted for a Portuguese teacher because we tried to make clear there would be no semantic differences between the previous and the reformatted scale. Also, this reviewer was able to comment the modifications in the scale since she was knowledgeable of the objectives of the scale. Besides, there are no rules as to how many doc- tors should be included in an adaptation scale committee and a multidisciplinary team is desirable 16.

This new revised version was submitted to a new pretest with 15 patients, again divided by three groups of five patients each, according to their educational level. The following observations were drawn:

[1] All patients with educational level $\geq 8$ years understood the whole scale, and no patients made any suggestions to the scale;

[2] All patients in the group of 5 to 7 years of schooling understood the whole scale;

[3] In the group with 4 or less years of education, three patients, all with 4 years of formal education, understood the whole scale. One patient could not understand confidently the item Severity of Pain, and one patient had difficulty in understanding the item Disability due to Pain.

This new tested version of the scale was much easier to be understood by all patients, and the rate of comprehension among patients with lower educational profile ( $\leq 4$ years of schooling) was around $87 \%$.

\section{DISCUSSION}

CD is a complex disorder and its burden for patients and health services is considerable. Thus, the need for accurate assessment of the impact it has on QOL of affected individuals and of treatment outcomes should not be underemphasized ${ }^{21}$. For these reasons, a comprehensive scale must be used to better evaluate these patients. However, there is no such instrument in Brazilian Portuguese aimed at measuring the physical and social burden of cervical dystonia. We then decided to perform the adaptation of the worldwide most commonly used cervical dystonia scale.

In this article, we describe the steps taken for the translation of the TWSTRS to Brazilian Portuguese. We aimed at producing a scale that can be used to comprehensively evaluate CD patients in any part of the Brazilian territory. As Brazil is a heterogeneous country, with many cultures and different educational background levels, this was not an easy task.

The translation consisted of two parts: In the first one, as suggested by Guillemin et al. ${ }^{16}$, all the steps were carefully taken into account to produce a scale capable of measuring the same phenomena as the original scale, without losing its reliability.

However, this adapted scale turned out to be completely understandable only for those over 8 years of formal education. Only some patients in the 5 to 7 years of schooling understand the whole scale and none of the patients with less than 4 years of formal education could completely understand the scale, with several items left unanswered. 
As many patients seen with CD in Brazil attend public hospitals, and those patients may be in the lower level of education, it would be possible that such individuals could not be properly evaluated with this adapted scale.

We then proceeded to the second part of the adaptation process, which consisted of a remodeling of the scale. Every item was modified, after the original scale's author consent (A.E.Lang, personal communication). This remodeling took in account the need to produce a scale able to measure exactly the same as the original scale ${ }^{16,19,20}$. To ensure it, the newly revised scale went through re-evaluation of semantic and idiomatic/cultural features by two judges, one of whom was a Portuguese university teacher.

Several authors state that the judge committee should be multidisciplinary ${ }^{16,22-24}$, and for this reason we decided to include a Portuguese linguist. Although she was not an expert in CD, she was told the objectives of the study and she had experience in translations. By doing this, we tried to diminish any semantic and idiomatic discrepancies that could bias the results.

After the committee evaluation, a new pre-test with 15 patients, subdivided in three groups of five patients each, according to educational background, was undertaken. We decided to include only 15 patients instead of 30 as in the first pre-test because we thought we would obtain the same results. This new version of the scale was much easier to be understood by almost all patients.

The cross-cultural process of a clinical scale must go beyond mere translation and cultural and linguist adaptation, taking also into account educational issues of the target population, should be taken into consideration ${ }^{24}$. This is of utmost importance, especially in a country like ours where there is a complex diversity of cultural and educational background among regions and within the same region, because it allows a measuring tool to evaluate a condition or a set of symptoms just as efficiently and reliably as the original scale ${ }^{14}$. We had this in mind, and a revised and compatible version of the scale had to be produced. We are now conducting the validation of the modified version of the TWSTRS.

\section{REFERENCES}

1. Consky ES, Lang AE. Clinical assessments of patients with cervical dystonia. In: Jankovic J, Hallet M (Eds). Therapy with botulinum toxin. New York: Dekker, 1994:211-237.

2. Ben-Shlomo Y, Camfield L, Warner T, ESDE collaborative group. What are the determinants of quality of life in people with cervical dystonia. J Neurol Neurosurg Psychiatry 2002;72:608-614.

3. Riski JE, Horner J, Nashold Jr BS. Swallowing function in patients with spasmodic torticollis. Neurology 1990;40:1443-1445.

4. Zetterberg L, Halvorsen K, Färnstrand C, Lundström E, Lindmark B, Aquilonius SM. Objective assessment of cervical dystonia: a pilot study. Acta Neurol Scand 2005;112:248-253.

5. O'Brien C, Brashear A, Cullis P, et al. Cervical dystonia severity scale reliability study. Mov Disord 2001;16:1086-1090.

6. Stacy M. Idiopathic cervical dystonia: an overview. Neurology 2000;55 (Suppl):S2-S8.

7. Gauthier S. Idiopathic spasmodic torticollis: pathophysiology and treatment. Can J Neurol Sci 1986;13:88-90.

8. Burke RE, Fahn S, Marsden CD, Bressman SB, Moskowitz C, Friedman J. Validity and reliability of a rating scale for the primary torsion dystonias. Neurology 1985;35:73-77.

9. Saunders-Pullman R, Soto-Valencia S, Costan-Toth C, et al. A new screening tool for cervical dystonia. Neurology 2005;64:2046-2049.

10. Tsui JK, Eisen A, StoessI AJ, Calne S, Calne DB. Double-blind study of botulinum toxin in spasmodic torticollis. The Lancet 1986;2:245-247.

11. Müller J, Wissel J, Kemmler G, et al. Craniocervical Dystonia Questionnaire (CDQ- 24): development and validation of a disease-specific quality of life instrument. J Neurol Neurosurg Psychiatry 2004;75:749-753.

12. Tarsy D. Comparison of clinical rating scales in treatment of cervical dystonia with botulinum toxin. Mov Disord 1997;12:100-102.

13. Cano SJ, Warner TT, Linacre JM, et al. Capturing the true burden of dystonia on patients: the Cervical Dystonia Impact Profile (CDIP-58). Neurology 2004; 63:1629-1633.

14. Folstein MF, Folstein SE, McHugh PR. "Mini-mental state": a practical method for grading the cognitive state of patients for the clinician. J Psychiatr Res 1975;12:189-198.

15. Brucki SM, Nitrini R, Caramelli P, Bertolucci PH, Okamoto I. Suggestions for utilization of the min-mental state examination in Brazil. Arq Neuropsiquiatr 2003;61:777-781.

16. Guillemin F, Bombardier C, Beaton D. Cross-cultural adaptation and quality of life measures: literature review and proposed guidelines. J Clin Epidemiol 1993;46:1417-1432.

17. Herdman M, Fox-Rushby J, Badia X. "Equivalence" and the translation and adaptation of health-related quality of life questionnaires. Qual Life Res 1997;6:237-247.

18. Berra S, Bustingorry V, Henze C, Díaz Mdel P, Rajmil L, Butinof M. Cross-cultural adaptation of the KIDSCREEN questionnaire to measure the health related quality of life in the 8 to 18 year-old Argentinean population. Arch Argent Pediatr 2009;107:307-314.

19. Herdman M, Fox-Rushby J, Badia X. A model of equivalence in the cultural adaptation of HRQoL instruments: the universalist approach. Qual Life Res 1998;7:323-335

20. Acquadro C, Conway K, Hareendran A, Aaronson N. European Regulatory Issues and Quality of Life Assessment (ERIQA). Literature review of methods to translate health-related quality of life questionnaires for use in multinational clinical trials. Value Health 2008;11:509-521.

21. Cano SJ, Hobart JC, Fitzpatrick R, Bhatia K, Thompson AJ, Warner TT. Patient-based outcomes of cervical dystonia: a review of rating scales. Mov Disord 2004;19:1054-1059.

22. Falcão DM, Ciconelli RM, Ferraz MB. Translation and cultural adaptation of quality of life questionnaires: an evaluation of methodology. J Rheumatol 2003; 30:379-385.

23. Guyatt $\mathrm{GH}$. The philosophy of health-related quality of life translation. Qual Life Res 1993;2:461-465

24. Novelli MMPC, Dal Rovere HH, Nitrini R, Caramelli P. Cross-cultural adaptation of the quality of life assessment scale on Alzheimer disease. Arq Neuropsiquiatr 2005;63:201-206. 